\title{
Prevalencia de anormalidades de células epiteliales y factores asociados en mujeres de un municipio rural colombiano
}

\author{
Hugo Grisales ${ }^{1}$, Ángela Patricia Vanegas ${ }^{2,3}$, Ángela M. Gaviria ${ }^{2,4}$, Jorge Castaño ${ }^{5}$, \\ Martín Alonso Mora ${ }^{6}$, Mauricio Borrero ${ }^{7}$, Carlos Rojas ${ }^{3}$, María Patricia Arbeláez ${ }^{3}$, \\ Gloria I. Sánchez ${ }^{2}$ \\ ${ }^{1}$ Grupo Demografía y Salud, Facultad Nacional de Salud Pública, Universidad de Antioquia, Medellín, \\ Colombia. \\ ${ }^{2}$ Grupo Infección y Cáncer, Facultad de Medicina, Universidad de Antioquia, Medellín, Colombia. \\ ${ }^{3}$ Grupo Epidemiología, Facultad Nacional de Salud Pública, Universidad de Antioquia, Medellín, \\ Colombia. \\ ${ }^{4}$ Escuela de Bacteriología, Colegio Mayor de Antioquia, Medellín, Colombia. \\ ${ }^{5}$ Departamento de Patología, Hospital Universitario San Vicente de Paúl, Facultad de Medicina, Universidad \\ de Antioquia, Medellín, Colombia. \\ ${ }^{6}$ Hospital San Vicente de Paúl, Pueblorrico, Colombia. \\ 7 Departamento de Ginecología y Obstetricia, Hospital Universitario San Vicente de Paúl, Facultad de \\ Medicina, Universidad de Antioquia, Medellín, Colombia.
}

Introducción. A pesar de la existencia de los programas de tamización basados en la citología, las tasas de cáncer de cuello uterino permanecen estables en Colombia. La descripción de los factores asociados a las lesiones precursoras de cáncer de cuello uterino es necesaria para establecer estrategias para su prevención.

Objetivo. Determinar la prevalencia de las anormalidades de células epiteliales escamosas y su asociación con los factores de riesgo descritos.

Materiales y métodos. Estudio transversal de población en 739 mujeres, seleccionadas en forma aleatoria. La información se recolectó mediante la citología y un cuestionario previamente validado. La medida de asociación fue la razón de prevalencia con su respectivo intervalo de confianza del 95\%. Las variables de confusión fueron controladas en un modelo de regresión logística multivariado.

Resultados. La prevalencia del evento fue de 15,8\%. Entre las mujeres con citología anormal, $10 \%$ presentó células escamosas atípicas de significado indeterminado; 3,9\%, lesión escamosa intraepitelial de bajo grado, y 1,9\%, lesión escamosa intraepitelial de alto grado. La regresión logística ajustada sugiere que los antecedentes de enfermedades de transmisión sexual, una citología anormal y tener dos o más parejas regulares/ocasionales durante la vida se asocian con la presencia del evento.

Conclusiones. La relación de anormalidades de células escamosas con conducta sexual refleja la asociación entre el virus del papiloma humano y lesiones preneoplásicas de cáncer de cuello uterino. El uso frecuente y el adecuado conocimiento sobre la citología, sugiere que aspectos tales como las dificultades con la calidad de la citología o el acceso al diagnóstico y tratamiento, pudieran explicar las altas tasas de cáncer de cuello uterino.

Palabras clave: neoplasias del cuello uterino/epidemiología, células epiteliales, frotis vaginal, citología, neoplasia intraepitelial del cuello uterino/prevención y control, Colombia.

Prevalence of epithelial squamous cell abnormalities and associated factors in women of a rural town of Colombia

Introduction. In spite of implementation of cytology-based cervical cancer screening in Colombia, mortality rates remain stable. The description of factors associated to cervical preneoplasic lesions is needed to establish strategies for mortality prevention.

Objective. The prevalence of epithelial squamous cell abnormalities was determined to explore the association of cytology abnormalities with described risk factors. 


\begin{abstract}
Materials and methods. This population-based, cross-sectional study included 739 women randomly selected by age. A validated face-to-face questionnaire and conventional cervical cytology were used to collect the information. To establish the association between cervical abnormalities and some qualitative variables, the independent chi squared test was used. We also calculated prevalence ratio with their $95 \%$ confidence intervals. A logistic regression model was used to explore variables that potentially explain cytology abnormalities.

Results. The prevalence of squamous cell abnormality was $15.8 \%$. Among women with abnormal cytology, $10 \%$ presented atypical squamous cells of undetermined significance, $3.9 \%$ low grade squamous intra-epithelial lesion and $1.9 \%$ high grade squamous intraepithelial lesion. The adjusted logistical regression analysis showed that history of sexual transmitted disease, two or more sexual partners during entire life and previous abnormal cytology were associated with cytology abnormalities.

Conclusion. The relation of epithelial squamous cell abnormalities with sexual behavior history reflexes the link between human papiloma virus infection and cervical cancer pre-neoplasic lesions. The frequency of use and knowledge about the purpose of cytology were factors that suggested other diagnostic limitations such as quality of cervical cytology or barriers to access health care. These latter factors may be the underlying basis for the high cervical cancer mortality rates.
\end{abstract}

Key words: uterine cervical neoplasms/epidemiology, epithelial cells, cervical cancer, vaginal smears, cytology, control and prevention, cervical intraepithelial neoplasia/prevention and control, Colombia.

En Latinoamérica y el Caribe, el cáncer de cuello uterino contribuye a más años de vida perdidos que la tuberculosis, la mortalidad materna o el síndrome de inmunodeficiencia adquirida (1). Anualmente se diagnostican alrededor de medio millón de casos invasivos y fallecen 231.000 mujeres por esta causa en el mundo. El $80 \%$ de estos casos y estas muertes ocurren en los países en desarrollo (2).

En Colombia, ocurren alrededor de 7.000 casos y mueren 3.300 mujeres por cáncer de cuello uterino anualmente; es la primera causa de muerte por cáncer en mujeres entre los 35 y 64 años (3). De acuerdo con el registro de tumores de Antioquia, en el 2005 se registraron 2.500 casos, de los cuales cerca de $30 \%$ fueron invasores.

A pesar del aumento en la cobertura de la citología tanto a nivel local como nacional (4), las tasas de mortalidad por esta causa continúan estables. El cáncer de cuello uterino es causado por el virus del papiloma humano (VPH) (5), el cual es

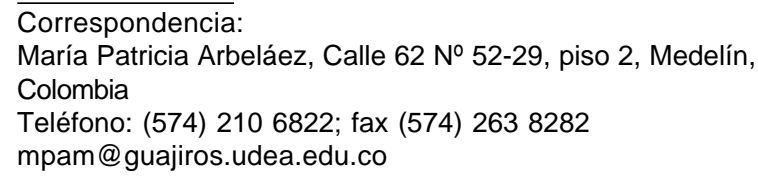

Recibido: 23/10/07; aceptado:13/03/08 transmitido sexualmente e infecta casi al $75 \%$ de la población sexualmente activa en el mundo (6). Una alta proporción de las mujeres infectadas desarrollan lesiones clínicamente evidentes, pero tanto la infección como estas lesiones son autocontroladas y desaparecen espontáneamente en el término de uno a dos años, y una proporción pequeña de mujeres infectadas con genotipos de alto riesgo, desarrollan lesiones de alto grado y eventualmente cáncer (7).

La tasa de prevalencia del virus del papiloma humano es mayor entre los 20 y los 25 años, etapa de mucha actividad sexual, y disminuye paulatinamente en las mujeres adultas. En mujeres mayores de 30 años la presencia del virus del papiloma humano indica una infección persistente que aumenta drásticamente el riesgo de desarrollo de lesiones de alto grado y cáncer.

Las anormalidades preneoplásicas detectadas mediante la citología, o prueba de Papanicolau (Bethesda 2001) (8), clasifica las anormalidades de células epiteliales escamosas en células escamosas atípicas de significado indeterminado (Atypical Squamous Cells of Undetermined Significance, ASCUS), con insuficientes hallazgos para su interpretación definitiva como de alto o bajo grado, en lesiones escamosas intraepiteliales 
de bajo grado y lesiones escamosas intraepiteliales de alto grado. Las lesiones escamosas intraepiteliales de bajo grado ocurren con mayor frecuencia en las mujeres jóvenes concomitantemente con el inicio de las relaciones sexuales y en su gran mayoría desaparecen espontáneamente, debido a un control efectivo de la infección viral. Las lesiones escamosas intraepiteliales de alto grado aparecen entre 5 y 10 años después de haberse adquirido la infección y son el producto de la persistencia del virus (7).

El objetivo de los programas de detección temprana es detectar a tiempo las lesiones escamosas intraepiteliales de alto grado mediante la citología y ofrecer un diagnostico definitivo rápido y tratamiento, el cual consiste en la remoción de la lesión antes de que ésta progrese a cáncer.

Los países industrializados previenen las muertes por este cáncer, porque estos programas incluyen la identificación de toda la población diana en bases de datos automatizadas, altas tasas de cobertura y repetición de la citología a cortos intervalos, contacto y seguimiento estricto de las mujeres con citología anormal y ofrecen acceso fácil e inmediato a la colposcopia, la biopsia y adecuado tratamiento. Aún más importante, es que la evaluación del control de la calidad de todas y cada una de las etapas mediante un plan de mejoramiento, que puede tomar hasta cinco años, es esencial.

En los países en desarrollo la instauración de este tipo de programas no ha sido posible. Una de las limitaciones es que, aún en excelentes condiciones de calidad, la citología sólo alcanza el $60 \%$ de sensibilidad para la neoplasia intraaepitelial de cuello uterino II (9) y en Latinoamérica la sensibilidad puede ser de $30 \%$ (10). La otra razón es que los actuales sistemas de salud no permiten la articulación de todos los niveles de atención para el oportuno diagnóstico y tratamiento.

Se están introduciendo a nivel mundial dos medidas de prevención contra el cáncer de cuello uterino. La vacuna profiláctica contra los virus del papiloma humano 16 y 18 puede reducir la incidencia de lesiones de alto grado hasta en el $50 \%$ si se aplica masivamente a las mujeres antes del inicio de las relaciones sexuales (11), y la prueba de ADN, la cual detecta el material genético del virus, ha mostrado una sensibilidad del $100 \%$ para la detección de la neoplasia intraaepitelial de cuello uterino II (12).

Para la implementación de ambas medidas en Colombia es necesario conocer: 1 ) la prevalencia de anormalidades de células epiteliales escamosas en mujeres de diferentes regiones de Colombia; 2) la prevalencia de los factores de riesgos asociados con el desarrollo de estas anormalidades, y 3) la prevalencia del virus del papiloma humano y de sus genotipos en las anormalidades de células epiteliales escamosas y los factores de riesgo para su adquisición.

Este constituye el primer informe de este estudio de población que describe la información sobre la prevalencia de las anormalidades de células epiteliales escamosas detectadas con citología de cuello uterino, en las mujeres de 15 o más años del municipio de Pueblorrico, Antioquia. Este es el segundo estudio de población para obtener una caracterización epidemiológica completa y estandarizada de las variables asociadas al desarrollo de cáncer de cuello uterino en la población colombiana y el primero en llevarse a cabo en una zona rural del país.

\section{Materiales y métodos}

\section{Diseño del estudio}

Se realizó un estudio de población de diseño transversal con el fin de determinar la prevalencia de las anormalidades de células epiteliales escamosas en la población de mujeres de 15 y más años residentes en el municipio de Pueblorrico, departamento de Antioquia, Colombia, y se exploró la asociación con factores de riesgo reportados en la literatura para el cáncer de cuello uterino.

El universo lo constituyeron 3.073 mujeres (1.301 de la zona urbana y 1.772 de la rural) mayores de 15 años. El muestreo fue probabilístico, aleatorio, estratificado con asignación proporcional por zona de residencia y grupos quinquenales de edad.

El marco muestral lo constituyó la información proporcionada por la alcaldía del municipio de Pueblorrico, donde meses atrás se había llevado 
a cabo un censo de población consistente en un archivo de datos en formato de texto donde se tenía toda la información de los habitantes del municipio, por grupos de edad, zona de residencia y sexo.

La unidad de análisis la constituyeron las mujeres de 15 o más años residentes en el mencionado municipio por, al menos, seis meses. Para el cálculo del tamaño de la muestra se utilizaron los datos del estudio de población de la prevalencia del virus del papiloma humano en Guacanaste, Costa Rica, el cual mostró una prevalencia de lesiones escamosas intraepiteliales de bajo grado de $2,2 \%$ (13). El error máximo permisible fue de $1,4 \%$ y la confianza considerada fue de $95 \%$. El tamaño de la muestra total fue de 739 mujeres, 313 de la zona urbana y el resto de la zona rural, distribuidas proporcionalmente en 11 diferentes grupos de edad (de 15 a 19 como primer grupo y 65 y más como último grupo).

\section{Recolección de la información}

Se utilizó una encuesta con preguntas cerradas, acerca de información sociodemográfica, historia reproductiva, actividad sexual, uso de la citología y hábito de fumar. El instrumento utilizado fue diseñado y validado por la Internacional Agency for Research on Cancer (IARC) en México, Costa Rica, Brasil y Colombia para encuestas de prevalencia de virus del papiloma humano.

La encuesta fue aplicada por personal de salud (auxiliar de enfermería, bacterióloga, enfermera profesional y médica), previamente entrenado en el Instituto Nacional de Cancerología en Bogotá, Colombia. El personal recibió, además, entrenamiento en la toma y manejo de las muestras.

Después de la entrevista, en un lugar privado y por personal desconocido por la población encuestada, se realizó un examen pélvico, el cual incluyó: inspección de la vulva, la vagina y el cuello uterino, para visualizar alguna alteración, y luego se procedió a la toma de la citología. Para la recolección de las células del exocervix (hocico de tenca) se utilizó una espátula de Ayre, rotándola suavemente $360^{\circ}$ hasta asegurar la toma de muestra de las diferentes partes del mismo.

Inmediatamente después, se insertó $1 \mathrm{~cm}$ de un citocepillo en el orificio endocervical e inmediata- mente se rotó tres veces en orientación contraria a las manecillas del reloj. El extendido de la muestra se preparó en una lámina de vidrio, se fijó inmediatamente con Cytospray® y se guardó en condiciones adecuadas para el transporte.

Las muestras se trasladaron al Departamento de Patología de la Universidad de Antioquia, donde fueron leídas por citólogas especializadas y por el patólogo del estudio. Para el diagnóstico citológico se siguió el sistema de Bethesda, 2001.

Los sesgos de información en el observador se controlaron utilizando como estrategia la estandarización a una auxiliar de enfermería, una enfermera jefe y una bacterióloga en la forma de la toma de la muestra, especuloscopia, sitio del cuello uterino para la toma de la muestra, forma de extendido de la placa, fijación y almacenamiento de las muestras y el envío de las mismas.

Los sesgos de selección se obviaron seleccionando las participantes de manera aleatoria y representativa de la población del municipio. Los sesgos de confusión se controlaron en el análisis mediante la utilización de la técnica multivariada de la regresión logística.

\section{Análisis estadístico}

En primer lugar, se calculó la prevalencia de anormalidades de células epiteliales escamosas y de cada una de las categorías del sistema de Bethesda, dividiendo el número de mujeres con diagnóstico positivo para dichas anormalidades, entre aquéllas a quienes se les hizo citología y aquéllas en las que se obtuvo un resultado citológico válido.

Luego, se cruzó cada una de las variables demográficas, de historia reproductiva, de actividad sexual, de citología y tabaquismo con las anormalidades de las células epiteliales escamosas, y se valoró la asociación del resultado de la citología con cada uno de los factores de riesgo, por medio de la razón de prevalencias (RP), acompañando ésta con el intervalo de confianza de $95 \%$ para dicha medida.

Para establecer la significación estadística se utilizó la prueba de ji al cuadrado de independencia; en todos los casos, el nivel de significación utilizado fue de $5 \%$. 
Para seleccionar el modelo explicativo de regresión logística, se llevó a cabo un procedimiento de selección por pasos, vía método de razón de verosimilitud, y se eligieron como variables candidatas a conformar el mismo aquéllas que en el análisis bivariado presentaron un valor de $\mathrm{p}$ menor de 0,25 (criterio de HosmerLemeshow) (14).

La información se procesó con Excel (Microsoft), SPSS versión 11.5 y Epidat versión 3.1 para el cálculo de la razón de prevalencias y sus correspondientes intervalos de confianza de $95 \%$.

\section{Consideraciones éticas}

Antes de la participación en el estudio, todas las participantes firmaron un consentimiento informado. El protocolo fue aprobado por el Comité de Bioética de la Universidad de Antioquia, el 21 de febrero de 2001.

\section{Resultados}

\section{Características generales de las mujeres encuestadas}

De 828 mujeres estudiadas, en 739 (89\%) se obtuvo una muestra de cuello uterino satisfactoria para realizar el Papanicolaou.

Entre las 739 mujeres encuestadas, más del 50\% refirieron que llevaban viviendo en el municipio trece o más años, 65,9\% pertenecía al nivel socioeconómico bajo, con predomino de un bajo nivel educativo, $26,7 \%$ con estudios primarios y $68,1 \%$ estaban casadas o en pareja.

La edad de las mujeres encuestadas varió entre 15 y 89 años con promedio de 39,8 $\pm 16,2$ años. La edad promedio en que tuvieron su primera menstruación, su primera relación sexual, su primer y su último hijo fue: $13,4 \pm 1,7 ; 19,8 \pm 4,8$; $23,1 \pm 12,3$ y $31,6 \pm 12,1$ años, respectivamente. Cincuenta por ciento de ellas iniciaron relaciones sexuales regulares a los 18 años, mientras que $12,3 \%$ refirieron haber tenido alguna enfermedad de transmisión sexual, entre las que predominaron la blenorragia $(24,2 \%$ ) y las verrugas genitales o condilomas $(20,1 \%)$. El número de parejas en total antes de los 20 años fue de dos o más en el 14,2\% de las mujeres.
El 18,4\% de las mujeres no conocía la utilidad de una citología y $19,4 \%$ nunca se la habían hecho. Entre las mujeres que dijeron haberse hecho una citología, la edad promedio en la cual se hicieron la primera fue $27,8 \pm 11,3$ años y la última fue a los 40,1 $\pm 15,9$ años. En cuanto a la frecuencia del uso de la citología, $28,8 \%$ de las mujeres afirmó que se la hacía una vez al año. El rango del número de citologías en toda la vida estuvo entre uno y cinco en $57,1 \%$ de las mujeres y 39 mujeres $(5,2 \%)$ refirieron que alguna vez habían tenido citologías anormales.

Cuando se averiguó sobre el consumo de cigarrillo, se encontró que aquellas mujeres que refirieron que al momento de la encuesta fumaban, 17,3\% consumía en promedio $7,8 \pm 8,7$ cigarrillos y 191 mujeres $(25,8 \%)$ dijeron que alguna vez en su vida habían fumado.

Cuando se indagó sobre los métodos de planificación, 48,2\% afirmó que utilizaba el dispositivo intrauterino y $12,9 \%$ dijo estar actualmente utilizando anticonceptivos orales. El $25 \%$ de las mujeres encuestadas afirmaron encontrarse en la menopausia.

\section{Prevalencia de anormalidades de células epiteliales escamosas y su distribución de acuerdo con las características demográficas}

En el cuadro 1 se presenta la prevalencia de anormalidades de células epiteliales escamosas entre las 739 mujeres que participaron en el estudio. El $84,2 \%$ presentó citología normal y $15,8 \%$ resultaron positivas para dichas anormalidades (IC95\% 13,3-18,7).

Entre las mujeres con anormalidades, 10\% (IC95\% 7,9-12,5) presentó células escamosas atípicas de significado indeterminado, 3,9\% (IC95\% 2,7-5,6) lesiones escamosas intraepiteliales de bajo grado y $1,9 \%$ (IC95\% 1,1-3,2) lesiones escamosas intraepiteliales de alto grado o cáncer.

En el cuadro 2 se presenta la distribución de las anormalidades de células epiteliales escamosas según las características demográficas de las mujeres participantes en el estudio. No se observó diferencia entre la proporción de dichas anormalidades cuando se compararon los 
resultados por área de residencia, nivel educativo o nivel socioeconómico de las mujeres.

Al considerar la edad en quinquenios, no se observó un gradiente de aumento de la proporción de positividad para anormalidades de células epiteliales escamosas (ji al cuadrado de tendencias, $p=0,729$ ) (no se presentan los datos). De igual manera, al comparar las proporciones de estas anormalidades entre mujeres de 15 a 44 años (edad de reproducción), con la proporción de las mismas entre las mujeres de 45 y más años, no se observaron diferencias estadísticas importantes.

Fue mayor la proporción de anormalidades de células epiteliales escamosas entre las mujeres casadas o en pareja (17,3\%), con respecto a las solteras $(10,0 \%)$, con diferencias estadísticamente significativas ( $\mathrm{RP}=1,7 ; \mathrm{IC} 95 \%$ 1,0-3,1) (cuadro 2).

Cuadro 1. Prevalencia de anormalidades de células epiteliales escamosas y clasificación de acuerdo con el sistema de Bethesda 2001 en mujeres de 15 y más años, Pueblorrico, Antioquia, 2003.

\begin{tabular}{lrrr}
\hline Diagnóstico citológico & $\mathbf{n}$ & Prevalencia & (IC 95\%)* $^{*}$ \\
\hline Células escamosas atípicas de significado indeterminado (ASCUS) & 74 & 10,0 & $(7,9-12,5)$ \\
Lesión intraepitelial escamosa de bajo grado & 29 & 3,9 & $(2,7-5,6)$ \\
Lesión intraepitelial escamosa de alto grado/cáncer & 14 & 1,9 & $(1,1-3,2)$ \\
Total anormalidades de células epiteliales escamosas & 117 & 15,8 & $(13,3-18,7)$ \\
Normal & 622 & 84,2 & $(81,3-86,7)$ \\
Total mujeres & 739 & & \\
\hline
\end{tabular}

*Intervalo de confianza del 95\% para la proporción o prevalencia

Cuadro 2. Prevalencia de anormalidades de células epiteliales escamosas según variables demográficas en mujeres de 15 y más años, Pueblorrico, Antioquia, 2003.

\begin{tabular}{|c|c|c|c|c|}
\hline & $\begin{array}{c}\text { ACEE } \\
\text { negativa }\end{array}$ & $\begin{array}{c}\text { ACEE } \\
\text { positiva }\end{array}$ & $\begin{array}{c}\% \\
\text { positivo }\end{array}$ & RP (IC 95\%) ${ }^{1}$ \\
\hline \multicolumn{5}{|l|}{ Área de residencia } \\
\hline Urbana & 264 & 49 & 15,6 & 1 \\
\hline Rural & 358 & 68 & 15,9 & $1,0(0,7-1,4)$ \\
\hline Total & 622 & 117 & & \\
\hline \multicolumn{5}{|l|}{ Edad (años) } \\
\hline 45 y más & 218 & 40 & 15,5 & 1 \\
\hline $15-44$ & 404 & 77 & 16,0 & $1,0(0,7-1,5)$ \\
\hline Total & 622 & 117 & & \\
\hline \multicolumn{5}{|l|}{ Estado civil } \\
\hline Soltera & 108 & 12 & 10 & 1 \\
\hline Casada/en pareja & 416 & 87 & 17,3 & $1,7(1,0-3,1)$ \\
\hline Divorciada/separada/viuda & 98 & 18 & 15,5 & $1,6(0,8-3,1)$ \\
\hline Total & 622 & 117 & & \\
\hline \multicolumn{5}{|l|}{ Nivel socioeconómico } \\
\hline Medio & 56 & 11 & 16,4 & 1 \\
\hline Bajo & 408 & 79 & 16,2 & $1,0(0,6-1,8)$ \\
\hline Sin estrato & 158 & 27 & 14,6 & $0,9(0,5-1,7)$ \\
\hline Total & 622 & 117 & & \\
\hline \multicolumn{5}{|l|}{ Nivel educativo } \\
\hline Secundaria y otros & 90 & 17 & 15,9 & 1 \\
\hline No terminó primaria & 244 & 40 & 14,1 & $0,9(0,5-1,5)$ \\
\hline Primaria & 161 & 36 & 18,3 & $1,2(0,7-1,9)$ \\
\hline Sin estudios formales & 127 & 24 & 15,9 & $1,0(0,6-1,8)$ \\
\hline Total & 622 & 117 & & \\
\hline
\end{tabular}

*RP: razón de prevalencias; IC: intervalo de confianza; ${ }^{1}$ Ajustado por edad 


\section{Anormalidades de células epiteliales escamosas según historia de salud sexual}

En el cuadro 3 se presenta la prevalencia de estas anormalidades de acuerdo con la historia de salud sexual de las mujeres participantes.

El $24,2 \%$, de las mujeres con anormalidades de células epiteliales escamosas refirieron haber tenido alguna enfermedad de transmisión sexual en su vida, mientras que $14,9 \%$ dijeron que nunca la habían tenido. El riesgo de presentar anormalidades de células epiteliales escamosas fue de 1,6 en mujeres con antecedente de enfermedad de transmisión sexual en comparación con mujeres sin este antecedente $(R P=1,6 \mathrm{IC} 95 \% 1,1-2,4)$.

Cuando se consideró el tipo de enfermedad de transmisión sexual, el riesgo de anormalidades de células epiteliales escamosas en aquellas mujeres que refirieron haber tenido condilomas, verrugas genitales o ambas, fue de 2,5 veces con respecto a las mujeres que afirmaron no haber tenido ninguna enfermedad de transmisión sexual $(\mathrm{RP}=2,5$; IC95\% 1,3-4,6).

No se observaron diferencias estadísticamente significativas entre la proporción de anormalidades de células epiteliales escamosas entre las mujeres que refirieron haber estado embarazadas o respecto a la edad de la primera relación sexual y a la edad de inicio de la actividad sexual regular (cuadro 3).

Cuando se consideraron las variables de comportamiento sexual, tales como número de compañeros sexuales, número de parejas ocasionales/regulares en el último año, número de parejas ocasionales/ regulares en toda la vida y número de parejas en total antes de los 20 años, se encontró que tener dos o más compañeros sexuales, sean ocasionales

Cuadro 3. Prevalencia de anormalidades de células epiteliales escamosas según variables reproductivas en mujeres de 15 y más años, Pueblorrico, Antioquia, 2003.

\begin{tabular}{|c|c|c|c|c|}
\hline & $\begin{array}{c}\text { ACEE } \\
\text { negativa }\end{array}$ & $\begin{array}{c}\text { ACEE } \\
\text { positiva }\end{array}$ & $\begin{array}{c}\% \\
\text { positivo }\end{array}$ & RP (IC 95\%) ${ }^{1}$ \\
\hline \multicolumn{5}{|l|}{ Haber tenido alguna ETS } \\
\hline No & 524 & 92 & 14,9 & 1 \\
\hline Sí & 69 & 22 & 24,2 & $1,6(1,1-2,4)$ \\
\hline No sabe & 14 & 3 & 17,6 & $1,2(0,4-3,4)$ \\
\hline Total & 607 & 117 & & \\
\hline \multicolumn{5}{|l|}{ Tipo de ETS } \\
\hline Ninguna & 524 & 92 & 14,9 & 1 \\
\hline Blenorragia & 16 & 6 & 27,3 & $1,8(0,9-3,7)$ \\
\hline Condiloma/verrugas genitales & 12 & 7 & 36,8 & $2,5(1,3-4,6)$ \\
\hline Otras & 38 & 8 & 17,4 & $1,2(0,6-2,2)$ \\
\hline Total & 590 & 113 & & \\
\hline \multicolumn{5}{|l|}{ Edad de la primera relación sexual } \\
\hline 25 y más & 71 & 14 & 16,4 & 1 \\
\hline $19-24$ & 188 & 34 & 15,3 & $0,9(0,5-1,6)$ \\
\hline$\leq 18$ & 339 & 69 & 16,9 & $1,0(0,6-1,7)$ \\
\hline Total & 598 & 117 & & \\
\hline \multicolumn{5}{|l|}{ Haber estado embarazada } \\
\hline No & 50 & 4 & 7,4 & 1 \\
\hline Sí & 548 & 113 & 17,1 & $2,3(0,9-6,0)$ \\
\hline Total & 598 & 117 & & \\
\hline \multicolumn{5}{|c|}{ Edad de inicio de la actividad sexual regular en años } \\
\hline 25 y más & 86 & 15 & 14,8 & 1 \\
\hline $19-24$ & 198 & 39 & 16,4 & $1,1(0,6-1,9)$ \\
\hline$\leq 18$ & 314 & 63 & 16,7 & $1,1(0,7-1,9)$ \\
\hline Total & 598 & 117 & & \\
\hline
\end{tabular}

${ }^{*}$ RP: razón de prevalencias; IC: intervalo de confianza; ${ }^{1}$ Ajustado por edad 
o regulares, aumenta el riesgo de presentar anormalidades de células epiteliales escamosas ( $R P=1,5 ;$ IC95\% 1,1-2,1) (cuadro 4).

\section{Anormalidades de células epiteliales escamosas y conocimientos y actitudes acerca de la citología de cuello uterino y uso del tabaco}

En el cuadro 5 se presentan los hallazgos sobre los conocimientos y actitudes acerca de la citología y la presencia de anormalidades de células epiteliales escamosas.

El $82 \%$ de las mujeres participantes mostró buen conocimiento acerca de la citología y el $80 \%$ se la habían hecho alguna vez en la vida (no se presentan los datos). La proporción de mujeres con anormalidades de células epiteliales escamosas o sin ellas según el conocimiento sobre la citología vaginal, uso de ésta alguna vez en la vida, frecuencia de realización de la misma y la edad cuando se hizo la primera o cuando se hizo la última y el número de citologías vaginales en toda la vida, no presentaron diferencias estadísticamente significativas.

El haber presentado alguna citología anormal previamente mostró asociación estadísticamente significativa con dichas anormalidades $(\mathrm{RP}=2,2$; IC95\% 1,4-3,6) (cuadro 5).

Cuadro 4. Prevalencia de anormalidades de células epiteliales escamosas según variables características de la actividad sexual en mujeres de 15 y más años, de Pueblorrico, Antioquia, 2003.

\begin{tabular}{|c|c|c|c|c|}
\hline & $\begin{array}{c}\text { ACEE } \\
\text { negativa }\end{array}$ & $\begin{array}{c}\text { ACEE } \\
\text { positiva }\end{array}$ & $\begin{array}{c}\% \\
\text { positivo }\end{array}$ & RP (IC 95\%) \\
\hline \multicolumn{5}{|c|}{ Pareja ocasional extramatrimonial } \\
\hline No & 300 & 45 & 13,0 & 1 \\
\hline Sí & 96 & 26 & 21,3 & $1,6(1,1-2,5)$ \\
\hline No responde & 118 & 34 & 22,4 & $1,7(1,1-2,6)$ \\
\hline Total & 514 & 105 & & \\
\hline \multicolumn{5}{|c|}{ Historia de ETS en la pareja } \\
\hline No & 385 & 67 & 14,8 & 1 \\
\hline Sí & 105 & 28 & 21,1 & $1,4(1,0-2,1)$ \\
\hline No sabe & 24 & 10 & 29,4 & $2,0(1,1-3,5)$ \\
\hline Total & 514 & 105 & & \\
\hline \multicolumn{5}{|l|}{ Uso del condón } \\
\hline Siempre & 22 & 6 & 21,4 & 1 \\
\hline A veces & 223 & 35 & 13,6 & $0,6(0,3-1,4)$ \\
\hline Nunca & 273 & 60 & 18,0 & $0,8(0,4-1,8)$ \\
\hline Total & 518 & 47 & & \\
\hline \multicolumn{5}{|c|}{ Número de compañeros sexuales (por más de seis meses) } \\
\hline$\leq 1$ & 484 & 87 & 15,2 & 1 \\
\hline 2 y más & 114 & 30 & 20,8 & $1,4(0,9-2,0)$ \\
\hline Total & 598 & 117 & & \\
\hline \multicolumn{5}{|c|}{ Número de parejas ocasionales/regulares en el último año } \\
\hline$\leq 1$ & 578 & 109 & 15,9 & 1 \\
\hline 2 y más & 29 & 8 & 21,6 & $1,4(0,7-2,6)$ \\
\hline Total & 607 & 117 & & \\
\hline \multicolumn{5}{|c|}{ Número de parejas ocasionales/regulares en toda la vida } \\
\hline$\leq 1$ & 383 & 61 & 13,7 & 1 \\
\hline 2 y más & 222 & 56 & 20,1 & $1,5(1,1-2,1)$ \\
\hline Total & 605 & 117 & & \\
\hline \multicolumn{5}{|c|}{ Número de parejas en total antes de los 20 años } \\
\hline$\leq 1$ & 527 & 94 & 15,1 & 1 \\
\hline 2 y más & 80 & 23 & 22,3 & $1,5(1,0-2,2)$ \\
\hline Total & 607 & 117 & & \\
\hline
\end{tabular}

RP: razón de prevalencias; IC: intervalo de confianza; ${ }^{1}$ Ajustado por edad 
Cuadro 5. Prevalencia de anormalidades de células epiteliales escamosas según variables referentes a la citología de cuello uterino en mujeres de 15 y más años, municipio de Pueblorrico, 2003.

\begin{tabular}{|c|c|c|c|c|}
\hline & $\begin{array}{c}\text { ACEE } \\
\text { negativa }\end{array}$ & $\begin{array}{c}\text { ACEE } \\
\text { positiva }\end{array}$ & $\begin{array}{c}\% \\
\text { positivo }\end{array}$ & $\mathrm{RP}(\mathrm{IC} 95 \%)^{1}$ \\
\hline \multicolumn{5}{|l|}{ ¿Sabe qué es una citología vaginal? } \\
\hline Sí & 508 & 95 & 15,8 & 1 \\
\hline No & 114 & 22 & 16,2 & $1,0(0,7-1,6)$ \\
\hline Total & 622 & 117 & & \\
\hline \multicolumn{5}{|l|}{ Uso de citología vaginal } \\
\hline Sí & 499 & 97 & 16,3 & 1 \\
\hline No & 123 & 20 & 14,0 & $0,9(0,6-1,3)$ \\
\hline Total & 622 & 117 & & \\
\hline \multicolumn{5}{|l|}{ Frecuencia de citología vaginal } \\
\hline Una vez al año & 178 & 35 & 16,4 & 1 \\
\hline Una vez cada 2-3 años & 193 & 30 & 13,5 & $0,8(0,5-1,3)$ \\
\hline Una vez cada 4-10 años & 97 & 23 & 19,2 & $1,2(0,7-2,6)$ \\
\hline Menos de una vez cada 10 años & 31 & 9 & 22,5 & $1,4(0,7-2,6)$ \\
\hline Total & 499 & 97 & & \\
\hline \multicolumn{5}{|l|}{ Historia de citología anormal } \\
\hline No & 473 & 83 & 14,9 & 1 \\
\hline Sí & 26 & 13 & 33,3 & $2,2(1,4-3,6)$ \\
\hline Total & 499 & 97 & & \\
\hline \multicolumn{5}{|l|}{ Edad primera citología (años) } \\
\hline$\leq 20$ & 128 & 22 & 14,7 & 1 \\
\hline$\geq 20$ años & 371 & 75 & 16,8 & $1,1(0,7-1,8)$ \\
\hline Total & 499 & 97 & & \\
\hline \multicolumn{5}{|l|}{ Edad última citología vaginal } \\
\hline $36-82$ & 280 & 45 & 13,8 & 1 \\
\hline $31-35$ & 76 & 20 & 20,8 & $1,5(0,9-2,4)$ \\
\hline$\leq 30$ & 143 & 32 & 18,3 & $1,3(0,9-2,0)$ \\
\hline Total & 499 & 97 & & \\
\hline \multicolumn{5}{|c|}{ Número de citologías vaginales en toda la vida } \\
\hline $11-36$ & 61 & 8 & 11,6 & 1 \\
\hline $6-10$ & 90 & 15 & 14,3 & $1,2(0,6-2,7)$ \\
\hline $3-5$ & 184 & 35 & 16,0 & $1,4(0,7-2,8)$ \\
\hline $1-2$ & 164 & 39 & 19,2 & $1,7(0,8-3,4)$ \\
\hline Total & 499 & 97 & & \\
\hline Ji al cuadrado de tendencias & & & & $\mathrm{p}=0,1032$ \\
\hline
\end{tabular}

RP: razón de prevalencia; IC; intervalo de confianza; ${ }^{1}$ Ajustado por edad

Cuando se indagó sobre el hábito de fumar en las mujeres encuestadas, no se encontraron diferencias significativas entre la proporción de anormalidades de células epiteliales escamosas con respecto al hecho de fumar en el momento de la encuesta 0 haber fumado alguna vez en la vida (cuadro 6).

\section{Análisis multivariado}

Se aplicó el método progresivo paso por paso con el fin de ajustar por las variables significativas. Las variables que se obtuvieron con la regresión se consideran como alternativas para tener en cuenta en un estudio analítico como presuntas variables que expliquen las anormalidades de células epiteliales escamosas.

Éstas fueron: antecedentes de enfermedad de trans-misión sexual de la mujer encuestada (OR=1,93; IC95\% 1,08-3,44), antecedente de una citología anormal (OR=2,73; IC95\% 1,21$6,16)$ y haber tenido dos o mas parejas ocasionales/regulares en la vida $(\mathrm{OR}=1,72$; IC95\% 1,07-2,76) (cuadro 7). 
Cuadro 6. Prevalencia de anormalidades de células epiteliales escamosas según variables referentes al hábito de fumar y valoración de la asociación en mujeres de 15 y más años, Pueblorrico, 2003.

\begin{tabular}{|c|c|c|c|c|}
\hline & $\begin{array}{c}\text { ACEE } \\
\text { negativa }\end{array}$ & $\begin{array}{c}\text { ACEE } \\
\text { positiva }\end{array}$ & $\begin{array}{c}\% \\
\text { positivo }\end{array}$ & RP (IC 95\%) ${ }^{1}$ \\
\hline \multicolumn{5}{|c|}{ ¿Actualmente fuma cigarrillo o tabaco? } \\
\hline No & 464 & 86 & 15,6 & 1 \\
\hline Sí & 106 & 22 & 17,2 & $1,1(0,7-1,7)$ \\
\hline Total & 570 & 108 & & \\
\hline \multicolumn{5}{|c|}{ ¿Alguna vez fumó cigarrillo o tabaco? } \\
\hline No & 425 & 84 & 16,5 & 1 \\
\hline Sí & 162 & 29 & 15,2 & $0,9(0,6-1,4)$ \\
\hline Total & 587 & 113 & & \\
\hline \multicolumn{5}{|c|}{ Años que fumó } \\
\hline$\leq 10$ & 90 & 18 & 16,7 & 1 \\
\hline$\geq 10$ & 72 & 11 & 13,3 & $0,8(0,4-1,6)$ \\
\hline Total & 162 & 29 & & \\
\hline \multicolumn{5}{|c|}{ Años hace que fuma } \\
\hline$\leq 10$ & 35 & 6 & 14,6 & 1 \\
\hline$\geq 10$ & 71 & 16 & 18,4 & $1,3(0,5-3,0)$ \\
\hline Total & 106 & 22 & & \\
\hline
\end{tabular}

RP: razón de prevalencias; IC: intervalo de confianza; ${ }^{1}$ Ajustado por edad

Cuadro 7. Regresión logística multivariado para las anormalidades en células epiteliales según diagnóstico citológico, en mujeres de 15 o más años, Pueblorrico, 2003.

\begin{tabular}{|c|c|c|c|c|c|c|}
\hline Variable & Coeficiente & Error estándar & Wald & $\mathbf{P}$ & OR & IC $95 \%$ \\
\hline \multicolumn{7}{|c|}{ Antecedente de ETS* } \\
\hline Sí & 0,658 & 0,296 & 4,928 & 0,026 & 1,93 & $1,080-3,449$ \\
\hline Historia de cit & & & & & & \\
\hline Sí & 1,006 & 0,415 & 5,870 & 0,015 & 2,733 & $1,212-6,166$ \\
\hline \multicolumn{7}{|c|}{$\begin{array}{l}\text { Número de parejas ocasionales/ } \\
\text { regulares en toda la vida }{ }^{\star \star \star}\end{array}$} \\
\hline$\geq 2$ & 0,545 & 0,240 & 5,138 & 0,023 & 1,724 & $1,077-2,76$ \\
\hline Constante & $-0,091$ & 0,470 & 0,038 & 0,846 & 0,913 & \\
\hline
\end{tabular}

Categoría de referencia: *sin antecedentes de ETS; ${ }^{* *}$ sin antecedentes de citología anormal; ${ }^{* * *}$ máximo una pareja en la vida

\section{Discusión}

Este estudio de población presenta la prevalencia y los factores de riesgo para anormalidades de células epiteliales escamosas en una población de mujeres de Pueblorrico, un municipio del oriente de Antioquia.

Las principales ventajas de este estudio es que implementó un diseño de población con muestreo aleatorio y proporcional por grupos de edad y lugar de residencia (rural $V s$. urbano) y utilizó instrumentos previamente validados en estudios similares llevados a cabo por la IARC (Lyon, Francia) y el Instituto Nacional de Cancerología de Bogotá.
La calidad y el diseño de este estudio son comparables a los de estudios de prevalencia de anormalidades de células epiteliales escamosas llevados a cabo en diversos lugares del mundo y especialmente en Latinoamérica $(13,15-17)$. El $65 \%$ de las mujeres encuestadas fueron de estrato socioeconómico bajo y sólo el $14 \%$ presentaron la secundaria como el más alto nivel educativo. Estas características contrastan ampliamente con el estudio de prevalencia llevado a cabo en Bogotá, en donde las mujeres participantes fueron contactadas en diferentes centros hospitalarios del área urbana y sólo el 35\% presentaban bajo nivel educativo y socioeconómico (16). 
El $15,8 \%$ de las mujeres participantes presentaban anormalidades de células epiteliales escamosas $y$, entre éstas, $10 \%$ presentaba células escamosas atípicas de significado indeterminado, 3,9\% lesiones escamosas intraepiteliales de bajo grado y $1,9 \%$ lesiones escamosas intraepiteliales de alto grado. En el estudio de Bogotá, la prevalencia de las lesiones escamosas intraepiteliales de bajo grado y de alto grado fue similar, pero el porcentaje de mujeres con células escamosas atípicas de significado indeterminado fue solamente del 2,2\% (18).

Esto contrasta no solamente con nuestros resultados, sino también con los obtenidos por Herrero y colaboradores en Guanacaste, Costa Rica, quienes describen una prevalencia de células escamosas atípicas de significado indeterminado cercana al 9,0\% (13). Ha sido claramente documentado que las células escamosas atípicas de significado indeterminado es la interpretación menos reproducible de todas las categorías del sistema Bethesda $(19,20)$. Por lo tanto, estas diferencias pueden reflejar dificultades en la implementación de criterios para la lectura de las citologías con esta categoría y sugiere la necesidad de un sistema que evalúe la reproducibilidad de los resultados de células escamosas atípicas de significado indeterminado en la citología en nuestro medio.

La prevalencia de anormalidades de células epiteliales escamosas fue similar para el área urbana y rural, debido a que muy posiblemente las características demográficas de ambas áreas son similares. El $65 \%$ de las mujeres entre 15 y 44 años de edad tenían anormalidades de células epiteliales escamosas mientras que la frecuencia de estos hallazgos fue menor (35\%) entre las mujeres mayores de 44 años. Esta distribución es semejante a lo descrito en otros estudios, en los cuales las anormalidades de la citología se presentan con mayor frecuencia tres años después del inicio de la actividad sexual y declinan paulatinamente en la población más adulta (7). La presencia de anormalidades de células epiteliales escamosas en mujeres mayores de 45 años, posiblemente, refleja la presencia de infecciones persistentes por virus del papiloma humano y, por lo tanto, son esta proporción de mujeres las que presentan alto riesgo de cáncer.
Las mujeres casadas o en pareja tuvieron mayor riesgo que las solteras para anormalidades de células epiteliales escamosas, lo cual podría explicarse por su actividad sexual o la actividad sexual de su pareja. Sólo el $16 \%$ de las participantes refirió haber tenido parejas ocasionales por fuera del matrimonio y, debido a que otros estudios en Latinoamérica han demostrado que la conducta sexual de los hombres incide directamente en el riesgo de desarrollo de cáncer en sus parejas (21), es posible sugerir que el riesgo descrito en nuestro estudio para las mujeres casadas en comparación con las solteras obedece a este mismo fenómeno.

Tanto en los análisis univariados como en el modelo de regresión logística, las variables que explican las anormalidades de células epiteliales escamosas en su mayoría estuvieron relacionadas con la conducta sexual de las participantes. Las variables que permanecieron seleccionadas por conferir un riesgo significativo para la presencia de estas anormalidades que se atribuyen a la conducta sexual fueron antecedente de una enfermedad de transmisión sexual ( $\mathrm{OR}=1,93$; IC95\% 1,08-3,44), y haber tenido más de dos parejas ocasionales o regulares durante toda la vida $(O R=1,72 ; \mathrm{IC} 95 \%$ 1,07-2,76).

Aunque no se puede excluir completamente el posible sesgo en la fuente de la información, estas observaciones posiblemente reflejan la relación que existe entre la infección con virus del papiloma humano, un virus de transmisión sexual, y las lesiones preneoplásicas y el cáncer de cuello uterino.

Actualmente, estamos adelantando las pruebas moleculares para determinar la distribución de los genotipos de virus del papiloma humano en exfoliaciones del cuello uterino tomadas en esta población para confirmar estas observaciones.

En nuestro estudio, el $57 \%$ de las mujeres refirieron haber tenido su primera relación sexual antes de los 18 años y, según la Encuesta Nacional de Demografía y Salud de Profamilia del 2005 , el $14 \%$ de las niñas colombianas en el área urbana habían iniciado actividad sexual a los 15 años; este porcentaje es superior (18\%) en el área rural (22). 
Se ha documentado que las vacunas profilácticas que están siendo introducidas en todo el mundo son muy efectivas en mujeres sin previa exposición a la infección con el virus del papiloma humano $(23,24)$ y que estas vacunas no son terapéuticas, o sea, no tienen la capacidad de eliminar infecciones adquiridas $(25,26)$. Es necesario llevar a cabo encuestas de prevalencia del virus del papiloma humano en poblaciones de adolescentes para determinar la edad a la cual se adquieren estas infecciones, de manera que se obtengan los mayores beneficios en la eventualidad de la introducción masiva de estas vacunas.

Uno de los hallazgos más importantes de este estudio es acerca del conocimiento y de las actitudes de las mujeres hacia la citología. El 82\% de las mujeres participantes mostraron buen conocimiento acerca de la citología y el $80 \%$ se habían hecho una citología alguna vez en la vida. Aún mas importante, en el modelo de regresión logística, el antecedente de citología anormal (OR=2,73; IC95\% 1,21-6,16) permaneció como explicación de anormalidades de células epiteliales escamosas. Los datos de este estudio y los de la Encuesta Nacional de Demografía y Salud de Profamilia, documentan que la cobertura de la citología en Colombia es alta, inclusive desde el 2003, y permanece alta hasta nuestros días (4).

En un estudio llevado a cabo en Medellín, se demostró que las mujeres tienen un buen conocimiento acerca de los beneficios del uso de la misma (27). Estas dos observaciones concuerdan con lo observado en México, en el que se demostró que el factor principal para la utilización del programa de detección temprana de cáncer es el conocimiento de la utilidad de la citología (28) e, indirectamente, sugieren que aspectos tales como las deficiencias en la calidad de la citología o las barreras en el acceso a los servicios de colposcopia y tratamiento pudieran explicar el hecho de que las tasas de mortalidad de cáncer de cuello uterino en Colombia permanezcan altas.

Las investigaciones sobre la evaluación de la calidad de la citología y el acceso a los servicios para mujeres con citologías anormales, así como sobre los factores de riesgo para la infección con virus del papiloma humano, ayudarán a establecer recomendaciones para la mejora de los programas de prevención secundaria y, eventualmente, para la consideración de alternativas tales como la prueba de virus del papiloma humano para la tamización y de la vacuna para la prevención primaria de cáncer de cuello uterino en regiones demográficamente similares a la estudiada.

\section{Agradecimientos}

Este trabajo no hubiera sido posible sin la decidida cooperación de las mujeres participantes en el estudio. Los autores expresan especial agradecimiento a Nubia Muñoz por su asesoría en la conducción del estudio, al Instituto Nacional de Cancerología por el entrenamiento en el uso de los instrumentos utilizados en el mismo, al personal médico y paramédico del Hospital San Vicente de Paúl de Pueblorrico y a las citotecnólogas Luciola Martínez, Carolina Morales, Nury Hoyos y Gloria Holguín, del Departamento de Patología de la Universidad de Antioquia.

\section{Conflicto de intereses}

Los autores declaran que no tienen conflictos de intereses.

\section{Financiación}

Este trabajo fue realizado mediante financiamiento de la Dirección Seccional de Salud de Antioquia (contrato № Cl-059-2002) y del Comité para el Desarrollo de la Investigación, CODI, de la Universidad de Antioquia (Código PB-3112-01).

\section{Referencias}

1. Yang BH, Bray FI, Parkin DM, Sellors JW, Zhang ZF. Cervical cancer as a priority for prevention in different world regions: an evaluation using years of life lost. Int J Cancer. 2004;109:418-24.

2. Parkin DM, Bray F. The burden of HPV-related cancers. Vaccine. 2006;24(Suppl.3):S11-25.

3. Piñeros M, Ferlay J, Murillo R. Cancer incidence estimates at the national and district levels in Colombia. Salud Pública Mex. 2006;48:455-65.

4. Piñeros M, Cendales R, Murillo R, Wiesner C, Tovar S. Pap test coverage and related factors in Colombia, 2005. Rev Salud Pública (Bogotá). 2007;9:327-41.

5. Walboomers JM, Jacobs MV, Manos MM, Bosch FX, Kummer JA, Shah KV, et al. Human papillomavirus is a necessary cause of invasive cervical cancer worldwide. J Pathol. 1999;189:12-9. 
6. Burchell AN, Winer RL, de Sanjose S, Franco EL. Chapter 6: Epidemiology and transmission dynamics of genital HPV infection. Vaccine. 2006;24 (Suppl. 3):S52-61.

7. Moscicki AB, Schiffman M, Kjaer S, Villa LL. Updating the natural history of HPV and anogenital cancer. Vaccine. 2006;24(Suppl.3):S42-51.

8. Solomon D, Davey D, Kurman R, Moriarty A, O'Connor D, Prey M, et al. The 2001 Bethesda System: terminology for reporting results of cervical cytology. JAMA. 2002;287:2114-9.

9. Kitchener HC, Castle PE, Cox JT. Achievements and limitations of cervical cytology screening. Vaccine. 2006;24(Suppl.3):S63-70.

10. Almonte M, Ferreccio C, Winkler JL, Cuzick J, Tsu $\mathrm{V}$, Robles S, et al. Cervical screening by visual inspection, HPV testing, liquid-based and conventional cytology in Amazonian Peru. Int $\mathrm{J}$ Cancer. 2007;121:796-802.

11. Goldie SJ, Kim JJ, Kobus K, Goldhaber-Fiebert JD, Salomon J, O'shea MK, et al. Cost-effectiveness of HPV 16, 18 vaccination in Brazil. Vaccine. 2007;25:6257-70.

12. Arbyn M, Sasieni P, Meijer CJ, Clavel C, Koliopoulos G, Dillner J. Clinical applications of HPV testing: A summary of meta-analyses. Vaccine. 2006;24(Suppl.3):S78-89.

13. Herrero R, Hildesheim A, Bratti C, Sherman ME, Hutchinson M, Morales $\mathrm{J}$, et al. Population-based study of human papillomavirus infection and cervical neoplasia in rural Costa Rica. J Natl Cancer Inst. 2000;92:464-74.

14. Hosmer DW, Lemeshow S. Applied Logistic Regression. New York: Wiley Interscience, John Wiley \& Sons, Inc; 2000.

15. Lazcano-Ponce E, Herrero R, Muñoz N, Cruz A, Shah K, Alonso P, et al. Epidemiology of HPV infection among Mexican women with normal cervical cytology. Int J Cancer. 2000;91:412-20.

16. Molano M, Posso H, Weiderpass $E$, van den Brule AJ, Ronderos M, Franceschi S, et al. Prevalence and determinants of HPV infection among Colombian women with normal cytology. Br J Cancer. 2002;87: 324-33.

17. Ferreccio C, Prado RB, Luzoro AV, Ampuero SL, Snijders PJ, Meijer CJ, et al. Population-based prevalence and age distribution of human papillomavirus among women in Santiago, Chile. Cancer Epidemiol Biomarkers Prev. 2004;13:2271-6.
18. Molano $\mathbf{M}$, van den Brule AJ, Posso $\mathbf{H}$, Weiderpass E, Ronderos M, Franceschi S, et al. Low grade squamous intra-epithelial lesions and human papillomavirus infection in Colombian women. $\mathrm{Br} \mathrm{J}$ Cancer. 2002;87:1417-21.

19. Stoler MH, Schiffman M. Interobserver reproducibility of cervical cytologic and histologic interpretations: realistic estimates from the ASCUS-LSIL Triage Study. JAMA. 2001;285:1500-5.

20. Confortini M, Carozzi F, Dalla Palma P, Ghiringhello B, Parisio F, Prandi S, et al. Interlaboratory reproducibility of atypical squamous cells of undetermined significance report: a national survey. Cytopathology. 2003;14:263-8.

21. Castellsague X, Bosch FX, Munoz $\mathbf{N}$. The male role in cervical cancer. Salud Pública Mex. 2003;45 (Suppl.3):S345-53.

22. Profamilia. Encuesta Nacional de Demografía y SaludENDS 2005. [Consultado: 16 de agosto de 2007]. Disponible en: http://www.profamilia.org.co/encuestas/ 01encuestas/2005resultados_generales.htm.

23. Paavonen J, Jenkins $D$, Bosch FX, Naud $P$, Salmeron J, Wheeler CM, et al. Efficacy of a prophylactic adjuvanted bivalent L1 virus-like-particle vaccine against infection with human papillomavirus types 16 and 18 in young women: an interim analysis of a phase III double-blind, randomized controlled trial. Lancet. 2007;369:2161-70.

24. Ault KA, Future II Study Group. Effect of prophylactic human papillomavirus L1 virus-like-particle vaccine on risk of cervical intraepithelial neoplasia grade 2 , grade 3 , and adenocarcinoma in situ: a combined analysis of four randomized clinical trials. Lancet. 2007;369:1861-8.

25. Hildesheim A, Herrero R, Wacholder S, Rodríguez AC, Solomon D, Bratti MC, et al. Effect of human papillomavirus 16/18 L1 viruslike particle vaccine among young women with preexisting infection: a randomized trial. JAMA. 2007;298:743-53.

26. Markowitz LE. HPV vaccines prophylactic, not therapeutic. JAMA. 2007;298:805-6.

27. Hanisch R, Gustat J, Hagensee ME, Baena A, Salazar JE, Castro MV, et al. Knowledge of Pap screening and human papillomavirus among women attending clinics in Medellin, Colombia. Aceptado. Int $\mathrm{J}$ Gynecol Cancer. 2007. doi: 10.1111/j.15251438.2007.01131.x

28. Flores Y, Bishai D, Lazcano E, Shah K, Lorincz A, Hernández $M$, et al. Improving cervical cancer screening in Mexico: results from the Morelos HPV Study. Salud Pública Mex. 2003;45(Suppl.3):S388-98. 